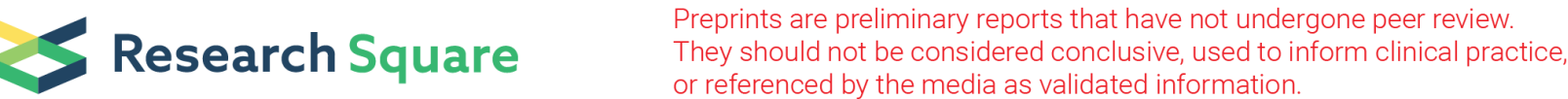

\section{Hexanol Biosynthesis From Syngas by Clostridium Carboxidivorans P7 - Investigation of Product Toxicity, Temperature Dependence and in Situ Extraction}

\section{Patrick Kottenhahn}

Department for Industrial Biotechnology, Fraunhofer Institute for Molecular Biology and Applied Ecology IME, Forckenbeckstr. 6, 52074 Aachen, Germany

\section{Gabriele Philipps}

Department for Industrial Biotechnology, Fraunhofer Institute for Molecular Biology and Applied Ecology IME, Forckenbeckstr. 6, 52074 Aachen, Germany

Stefan Jennewein ( $\nabla$ stefan.jennewein@ime.fraunhofer.de)

Department for Industrial Biotechnology, Fraunhofer Institute for Molecular Biology and Applied Ecology IME, Forckenbeckstr. 6, 52074 Aachen, Germany https://orcid.org/0000-0002-1625-5484

\section{Research}

Keywords: product toxicity, bioeconomy, carbon fixation, C1 compounds, Clostridium ljungdahlii, Clostridium carboxidivorans, in situ extraction, biofuels, fatty acid analysis, cell membrane

Posted Date: September 22nd, 2020

DOl: https://doi.org/10.21203/rs.3.rs-72740/v1

License: (c) (i) This work is licensed under a Creative Commons Attribution 4.0 International License. Read Full License 


\section{Abstract}

\section{Background}

Clostridium carboxidivorans $\mathrm{P} 7$ converts synthesis gas (also called syngas, a mixture of $\mathrm{CO}, \mathrm{CO}_{2}$ and $\mathrm{H}_{2}$ ) directly into industrially relevant alcohols (hexanol, butanol and ethanol) and their corresponding acids (caproate, butyrate and acetate). The product titers and ratios are highly dependent on fermentation parameters and the compositions of syngas as well as the growth medium. Hexanol titers produced by $C$. carboxidivorans $\mathrm{P} 7$ have recently been improved by optimizing these conditions, but little is known about the toxicity of hexanol towards Clostridium species. We hypothesized that the hexanol titers currently produced by $C$. carboxidivorans $\mathrm{P} 7$ are limited by product toxicity.

\section{Results}

We tested our hypothesis by analyzing $\mathrm{IC}_{50}$ values for hexanol at $30^{\circ} \mathrm{C}$ and $37^{\circ} \mathrm{C}$, which we determined as $17.5 \pm 1.6 \mathrm{mM}$ and $11.8 \mathrm{mM} \pm 0.6 \mathrm{mM}$, respectively, indicating a major influence of growth temperature on hexanol sensitivity. We found that $20 \mathrm{mM}$ hexanol was acutely toxic to $C$. carboxidivorans $\mathrm{P} 7$ at $30^{\circ} \mathrm{C}$ and growth was already completely inhibited in the presence of $15 \mathrm{mM}$ hexanol at $37^{\circ} \mathrm{C}$. Membrane fatty acid analysis showed that the cell membrane composition of $C$. carboxidivorans adapted strongly to the higher growth temperature but surprisingly did not change significantly when grown in the presence of $10 \mathrm{mM}$ hexanol.

To avoid product toxicity during hexanol production we added oleyl alcohol as an extraction solvent. At $30^{\circ} \mathrm{C}$, addition of the solvent increased total hexanol titers nearly 2.5 -fold from 10.5 to $23.9 \mathrm{mM}$. However hexanol titers decreased from 7.0 to $5.6 \mathrm{mM}$ in the presence of oleyl alcohol at $37^{\circ} \mathrm{C}$. At $30^{\circ} \mathrm{C}$, the extraction phase contained large amounts of hexanol $(448 \pm 130 \mathrm{mM})$ and butanol $(102 \pm 20 \mathrm{mM})$. Values were lower at $37^{\circ} \mathrm{C}$ with $101 \pm 27 \mathrm{mM}$ hexanol and $50 \pm 6 \mathrm{mM}$ butanol. Growth was not inhibited by oleyl alcohol. Biomass remained high in the presence of oleyl alcohol at $30^{\circ} \mathrm{C}$, but rapidly decreased in the absence of the solvent. At $37^{\circ} \mathrm{C}$ biomass decreased even in the presence of oleyl alcohol. We tested corn oil and sunflower seed oil as potentially cheaper and more sustainable extraction solvents. While oleyl alcohol displayed the highest extraction efficiency for hexanol, total hexanol titers were similar with all solvents tested.

\section{Conclusions}

Both, product toxicity and growth temperature were identified as limiting factors during the conversion of syngas to hexanol by $C$. carboxidivorans $\mathrm{P} 7$. At $30^{\circ} \mathrm{C}$ the addition of a biocompatible solvent led to detoxification and a significant increase in hexanol titers, $80 \%$ higher than highest previously reported titers. These findings help to mediate the limitation of product toxicity in hexanol production from syngas for the development of more efficient process designs and production strains.

\section{Background}


The utilization of industrial process gases or waste gases to produce fuels and platform chemicals could help to counter the effects of climate change. The production of organic alcohols such as butanol is particularly attractive based on their higher energy density and lower hygroscopic activity compared to ethanol [1]. Butanol can be used directly as a so-called drop-in fuel because it is compatible with current combustion engine designs [2], in addition it is also suitable as an industrial solvent or a platform chemical for conversion into polymers [1]. The similar structure but longer chain length of hexanol also makes this alcohol suitable for these and other applications. Recent publications by companies such as Evonik Creavis $\mathrm{GmbH}$ and Siemens AG concerning butanol and hexanol production from syngas are evidence for increasing interest in these processes from an industrial perspective [3].

Syngas, a mixture of $\mathrm{CO}, \mathrm{CO}_{2}$ and $\mathrm{H}_{2}$ in differing amounts, can be metabolized by a heterogeneous group of bacteria known as acetogens. Acetogenesis is a physiological rather than a phylogenetic trait and is distributed across 23 genera, with many representatives in the genus Clostridium [4]. Unlike chemical catalysts, these bacteria can metabolize syngas under ambient conditions and can accommodate syngas substrates varying in composition and impurity levels $[5,6]$. Sustainable sources of syngas include process gases from steel mills or it can be produced by organic waste gasification plants. In conclusion, the conversion of such resources to value added chemicals could help to offset industrial greenhouse gas emissions. One promising species for this application is Clostridium carboxidivorans P7. The strain was isolated by screening for species that grow well on $\mathrm{CO}$ [7] and is noted for its rare ability to synthesize C6 compounds like hexanol directly from syngas [8-10].

Fermentation with solventogenic acetogens usually involves two production phases. The first is an exponential growth phase that involves acetogenesis and is directly linked to energy conservation [1113]. Once acetate and other primary products accumulate, the bacteria shift from acetogenesis to solventogenesis. During solventogenesis, the primary acidic products are reduced to the corresponding alcohols. With electron-rich substrates such as $\mathrm{CO}$, this allows the cells to reestablish redox homeostasis and to conserve additional energy. For the reduction of acids to the corresponding alcohols via alcohol dehydrogenase, NADH is used as the electron donor. The regeneration of reduced NADH is coupled to energy conservation via the buildup of an ion gradient over the membrane, fueling an ATP synthase [12]. Thus, when the formation of more organic acids is inhibited due to already high product concentrations or low $\mathrm{pH}$, production of solvents allows for additional energy conservation, especially when $\mathrm{CO}$ is used as the primary electron donor instead of $\mathrm{H}_{2}$ or an aldehyde:ferredoxin oxidoreductase is used instead of an alcohol dehydrogenase [13]. Because solventogenesis generally occurs in the later phases of growth, it is often associated with sporulation, although sporulation and solventogenesis tend to be regulated independently in Clostridium species [14-18].

Acetogens metabolize syngas via the Wood-Ljungdahl pathway, also known as the reductive acetyl-CoA pathway. Two molecules of $\mathrm{C} 1$ substrate are used to form a coenzymeA-bound acetyl group using electrons derived from $\mathrm{H}_{2}$ or $\mathrm{CO}$. Acetyl-CoA can then be converted to the $\mathrm{C} 2$ products acetate and ethanol for energy conversion, or utilized to produce biomass [12]. Some acetogens, including $C$. carboxidivorans $\mathrm{P} 7$, can extend the carbon chain to synthesize the $\mathrm{C} 4$ products butyrate and butanol, and the $\mathrm{C} 6$ products 
caproate and hexanol $[7,10]$. The ability of $C$. carboxidivorans $\mathrm{P} 7$ to produce caproate and hexanol from syngas can be enhanced by medium and process optimization $[10,19,20]$. For example, the optimization of trace element composition significantly improved bacterial growth, leading to yields of $1.33 \mathrm{~g} / \mathrm{L}$ $(13.0 \mathrm{mM})$ hexanol in combination with a temperature shift to $25^{\circ} \mathrm{C}$ after an initial growth phase at $37^{\circ} \mathrm{C}$ [19]. Furthermore, a two-step fermentation process has been developed to overcome the limitations of biphasic growth. Generally, most cell growth is associated with acetogenesis and growth is inhibited as the medium becomes more acidic and a switch towards solventogenesis is triggered. In this two-step fermentation process however, the first fermenter is held at $\mathrm{pH} 6$ for acetogenesis, allowing the accumulation of biomass, acetate and ethanol. The medium in the first fermenter is renewed and some of the broth is flushed to a second fermenter with cell retention at $\mathrm{pH} 5$ for solventogenesis. This allows longer fermentation runs because the first fermenter continuously provides cells for the formation of products with longer carbon chain lengths [20].

Although the effect of acids during fermentation is well understood, and toxicity data are available for both, ethanol and butanol, there is no data concerning the potential toxicity of hexanol towards $C$. carboxidivorans $\mathrm{P} 7$ [9]. As reported for $C$. carboxidivorans $\mathrm{P} 7$ grown at $30^{\circ} \mathrm{C}$ with $\mathrm{CO}$ as a sole carbon and energy source, a $50 \%$ decrease in final biomass was caused by either $14-14.50 \mathrm{~g} / \mathrm{L}$ butanol or $35 \mathrm{~g} / \mathrm{L}$ ethanol. $I_{50}$ values for ethanol and butanol for initial growth rates could be deduced from the growth rates reported to lie between $5-10 \mathrm{~g} / \mathrm{L}$ and $20-25 \mathrm{~g} / \mathrm{L}$, respectively. Furthermore, when a mixture of both alcohols was used, the drop in growth rates was even more pronounced compared to the single alcohols, indicating greater adverse effects due to co-toxicity [21]. In another study, the reported $\mathrm{IC}_{50}$ value of butanol for $C$. carboxidivorans $\mathrm{P} 7$ grown at $25^{\circ} \mathrm{C}$ with a gas mixture of $32 \% \mathrm{CO}, 32 \% \mathrm{H}_{2}, 28 \% \mathrm{~N}_{2}$ and $8 \%$ $\mathrm{CO}_{2}$ was $4.12 \mathrm{~g} / \mathrm{L}$, with complete inhibition at $13.92 \mathrm{~g} / \mathrm{L}$. In this study, the $\mathrm{IC}_{50}$ value for butanol was also calculated using the datasets of the previous study as $6.36 \mathrm{~g} / \mathrm{L}[21,22]$. The $\mathrm{IC}_{50}$ of hexanol is expected to be even lower than the values reported for butanol and ethanol, given that alcohol toxicity increases with chain length and the corresponding nonpolar characteristics of the carbon chain as reported for Escherichia coli [23]. Growth of the model acetogen $C$. ljungdahlii has been tested in the presence of hexanol. With $10 \mathrm{mM}$ hexanol $(1 \mathrm{~g} / \mathrm{L})$, growth yields were only slightly impaired, while with concentrations $\geq 50 \mathrm{mM}(5 \mathrm{~g} / \mathrm{L})$ growth was inhibited completely [24].

Product inhibition and toxic effects during alcohol production can be avoided by the use of oleyl alcohol ((Z)-Octadec-9-en-1-ol) as a biocompatible extraction solvent, as already reported for acetone-butanolethanol (ABE) fermentation [25] as well as other hydrophobic products [26] and syngas fermentation [3]. Hydrophobic extraction solvents are advantageous because the product is transferred to an organic phase, reducing the concentration of toxic products in the aqueous fermentation broth containing the cells. Furthermore, the low polarity and low solubility of hexanol in water can be exploited to concentrate the product in the extraction phase. Phase separation also facilitates continuous product harvesting because, without constant agitation, the lipophilic phase containing the hexanol forms a layer on top of the fermentation broth. The extraction solvent is therefore easy to remove and replace, providing an opportunity for extended fermentation runs with minimal downtime. Finally, the large difference between 
the boiling points of hexanol $\left(157^{\circ} \mathrm{C}\right)$ and oleyl alcohol $\left(330-360^{\circ} \mathrm{C}\right)$ allows rapid product recovery by distillation and potential recycling of the solvent. We therefore measured the toxicity of hexanol towards C. carboxidivorans P7 and the model acetogen C. Ijungdahlii, and compared the use of oleyl alcohol to other extraction solvents for the in-line extraction during the production of hexanol during syngas fermentation in order to increase hexanol titers.

\section{Results}

\section{The acute toxicity of hexanol}

To determine whether the ability to produce hexanol confers increased resistance to this product, we compared the growth of the natural hexanol producer $C$. carboxidivorans $\mathrm{P} 7$ with that of the model acetogen $C$. ljungdahlii, which does not produce hexanol. Furthermore, given that $C$. ljungdahlii is well researched and genetically accessible, a significantly higher tolerance towards hexanol would turn this organism into a potential biocatalyst for hexanol production compared to the less researched natural hexanol producer $C$. carboxidivorans. Acutely lethal hexanol concentrations were determined in growth inhibition assays. Cells growing in anaerobic glass roll tubes containing modified minimal medium with syngas as a growth substrate were exposed to $0,10,20,30$ or $40 \mathrm{mM}(0,1,2,3$ or $4 \mathrm{~g} / \mathrm{L})$ hexanol during the exponential growth phase (Fig. 1A,B).

Interestingly, despite the difference in metabolic capability, we observed no difference in hexanol tolerance between these strains under the conditions tested. There was no effect on the growth of either strain in the presence of $10 \mathrm{mM}$ hexanol, but exposure to $\geq 20 \mathrm{mM}$ caused an increase in turbidity immediately after the hexanol was added and turbidity remained stable thereafter. Furthermore, gas consumption ceased in cultures with hexanol concentrations $\geq 20 \mathrm{mM}$. This indicated the significant inhibition of growth and syngas utilization. To determine whether the cells were killed or merely dormant, $500-\mu \mathrm{L}$ aliquots of cells were removed after $24 \mathrm{~h}$ and transferred to fresh medium without hexanol to see whether recovery was possible. The cultures originally exposed to 0 and $10 \mathrm{mM}$ hexanol recovered fully, whereas only $50 \%$ of the cultures originally exposed to $20 \mathrm{mM}$ hexanol were able to regrow. There was no regrowth in the cultures exposed to higher concentrations of hexanol. These findings indicate that exposure to $20 \mathrm{mM}$ hexanol for $24 \mathrm{~h}$ killed nearly all of the cells, and a $500-\mu \mathrm{L}$ aliquot contained on average less than one viable cell. At higher hexanol concentrations, significant macroscopic flocculation of the cells was observed (Fig. 1C), indicating that hexanol affects the cell membranes. Flocculation was also observed during fed-batch bottle fermentations after 3-4 days, and has been reported in other studies focusing on the production of alcohols [19]. The lack in major differences in hexanol tolerance between both clostridial species led to the decision to focus on the natural hexanol producer $C$. carboxidivorans for further characterization.

Hexanol titers at the onset of inhibition and calculation of IC ${ }_{50}$ values 
Having evaluated the acute toxicity of hexanol, we next determined the minimal inhibitory concentration (MIC) and $\mathrm{IC}_{50}$ for $C$. carboxidivorans $\mathrm{P} 7$. The $\mathrm{MIC}$ is the highest hexanol concentration, at which growth is still observed, whereas the $\mathrm{IC}_{50}$ is the hexanol concentration at which the initial growth rate is reduced by $50 \%$. Given the reported positive effect of lower incubation temperature on alcohol production [19, 27], we decided to exemplarily investigate both parameters, MIC and IC $\mathrm{C}_{50}$, at $37^{\circ} \mathrm{C}$ as well as $30^{\circ} \mathrm{C}$. The lower temperature was chosen to achieve an acceptable tradeoff between potentially increased resilience towards hexanol at lower temperatures and faster growth at higher temperatures. By still allowing the cells to grow continuously without a distinct temperature shift, this setup will facilitate easier scale up and continuous process design.

As above, cells were grown in anaerobic glass tubes containing modified minimal medium and syngas as a growth substrate. Since now exact inhibitory titers of hexanol were investigated, we chose to add hexanol before inoculation to avoid the increase in observed turbidity in the experiment shown in Fig. 1. For experiments at $30^{\circ} \mathrm{C}$, the medium was supplemented with $0,12,14,15,16,18,20$ or $22 \mathrm{mM}$ hexanol. Exponential growth began immediately after inoculation. On the second day at $30{ }^{\circ} \mathrm{C}$ in the presence of hexanol, the growth rates decreased rapidly and a near linear growth profile was observed (Supplementary Fig. 1). Both, the initial growth rates and final biomass yields were lower in cultures with higher hexanol concentrations. Cultures supplemented with $22 \mathrm{mM}$ hexanol did not show significant growth, and cultures supplemented with $20 \mathrm{mM}$ hexanol doubled once on the first day and then stagnated ( $\mathrm{MIC}=18-20 \mathrm{mM}$ hexanol). After two days of growth, cultures containing $12 \mathrm{mM}$ hexanol achieved only $\sim 50 \%$ of the biomass yield of the control without added hexanol, confirming that significant growth inhibition occurred even at low hexanol titers. The $\mathrm{IC}_{50}$ for hexanol at $30^{\circ} \mathrm{C}$ was determined as $17.5 \pm 1.6 \mathrm{mM}$ based on normalized initial growth rates. At $37^{\circ} \mathrm{C}$, the impact of $0,7,10,12$, 13,14 and $15 \mathrm{mM}$ hexanol was investigated and an $\mathrm{IC}_{50}$ value of $11.8 \mathrm{mM} \pm 0.6 \mathrm{mM}$ was calculated from the growth rates observed. At titers $\geq 15 \mathrm{mM}$ no growth was observed at $37^{\circ} \mathrm{C}(\mathrm{MIC}=13-14 \mathrm{mM}$ hexanol). In conclusion, a shift from $37^{\circ} \mathrm{C}$ to $30^{\circ} \mathrm{C}$ leads to a $48 \%$ increase in hexanol tolerance. Doubling times increased by $33 \%$ from $7.5 \pm 0.2 \mathrm{~h}$ at $37^{\circ} \mathrm{C}$ to $10.1 \pm 1.0 \mathrm{~h}$ at $30^{\circ} \mathrm{C}$.

\section{Oleyl Alcohol Avoids Product Toxicity}

Oleyl alcohol has been widely used as an extraction solvent in ABE fermentation and recently also in syngas fermentation [3], but has not yet been used in syngas fermentations with $C$. carboxidivorans. We therefore cultivated cells in modified minimal medium with syngas as above, but also added $5 \%(\mathrm{v} / \mathrm{v})$ oleyl alcohol and $100 \mathrm{mM}$ hexanol. Both $C$. carboxidivorans P7 and $C$. ljungdahlii were able to grow robustly, confirming that oleyl alcohol does not impair growth with gaseous substrates and is able to detoxify the medium with hexanol titers of at least twice the concentration soluble in water. However, in the presence of cells the oleyl alcohol formed microscopic bubbles or vesicles that increased the optical density of the medium over time (data not shown), so it was not possible to collect accurate values 
directly. For subsequent experiments, cells were therefore harvested and washed by centrifugation before $\mathrm{OD}_{600}$ values were determined.

\section{In situ hexanol extraction during fed-batch bottle fermentation}

To evaluate the effect of the extraction solvent on product formation, fedbatch bottle fermentations were carried out in the presence or absence of $4 \%(\mathrm{v} / \mathrm{v})$ oleyl alcohol. We inoculated $C$. carboxidivorans P7 cells into $250-\mathrm{mL}$ serum flasks containing $25 \mathrm{~mL}$ medium at either $30^{\circ} \mathrm{C}$ or $37^{\circ} \mathrm{C}$ and fed them with syngas $\left(65 \% \mathrm{CO}, 15 \% \mathrm{CO}_{2}, 15 \% \mathrm{~N}_{2}\right.$ and $\left.5 \% \mathrm{H}_{2}\right)$ at 1 bar overpressure, with gas-phase renewal every $24 \mathrm{~h}$ for 5 days. Maximum biomass at $30^{\circ} \mathrm{C}$ was reached after 5 days of growth with $\mathrm{OD}_{600}$ values of $6.3 \pm 0.6$ in the control culture (Fig. 2A) and $6.2 \pm 0.7$ in the culture containing $4 \%(\mathrm{v} / \mathrm{v}$ ) oleyl alcohol (Fig. 2B), confirming our earlier observation that oleyl alcohol does not affect growth behavior. At $37^{\circ} \mathrm{C}$, maximum biomass was reached one day earlier with $\mathrm{OD}_{600}$ values of $4.9 \pm 0.3$ in the control (Fig. 2C) and $5.4 \pm 0.6$ in the cultures containing oleyl alcohol (Fig. 2D). Although growth was faster at the higher temperature, incubation at $30^{\circ} \mathrm{C}$ led to higher biomass formation. Furthermore, maximum $\mathrm{OD}_{600}$ values at $30^{\circ} \mathrm{C}$ remained stable for several days in the presence of oleyl alcohol but decreased in the absence of the solvent, confirming its detoxifying effect. At $37^{\circ} \mathrm{C}$ however, $\mathrm{OD}_{600}$ values decreased both in the presence and absence of oleyl alcohol.

Under all conditions, cells in the exponential growth phase produced mostly acetate and ethanol, and later butyrate and butanol. As expected, at $37^{\circ} \mathrm{C}$ products were initially produced faster and in higher amounts compared to $30^{\circ} \mathrm{C}$. Hexanol production started during the late exponential to early stationary phase, and the acetate and butyrate titers decreased in all cultures. The final hexanol titers in the aqueous phase after 8 days at $30^{\circ} \mathrm{C}$ were $10.5 \pm 2.2 \mathrm{mM}$ in the control culture and $6.0 \pm 1.2$ in the culture containing $4 \%$ oleyl alcohol, whereas the titers of all other fermentation products measured in the aqueous phase were not influenced by the extraction solvent (Fig. 3A). In the oleyl alcohol phase, the hexanol concentration was $448 \pm 130 \mathrm{mM}$ (Fig. 3B), corresponding to $17.9 \mathrm{mM}$ normalized for the culture volume. When added to the $6.0 \mathrm{mM}$ hexanol in the aqueous phase, the overall hexanol titer was $23.9 \mathrm{mM}$, representing a nearly 2.5 -fold increase compared to the control without oleyl alcohol (Fig. 4A). Two thirds of the total hexanol were found in the oleyl alcohol phase, corresponding to a concentration factor of approximately 60 over the aqueous phase. In addition to hexanol, the oleyl alcohol phase contained 102 $\pm 20 \mathrm{mM}$ butanol, $126 \pm 43 \mathrm{mM}$ ethanol and traces of caproate. Neither acetate nor butyrate were present in the extraction phase.

At $37^{\circ} \mathrm{C}, 7.0 \pm 0.5 \mathrm{mM}$ hexanol were produced in the absence of oleyl alcohol. In the presence of the extraction solvent a total of only $5.6 \pm 1.3 \mathrm{mM}$ hexanol was observed with $1.6 \pm 0.4 \mathrm{mM}$ of the total hexanol located in the aqueous phase and titers of $101 \pm 27 \mathrm{mM}(4.0 \pm 1.0 \mathrm{mM}$ normalized to the culture volume) in the extraction phase (Figs. 3D and 4B). The extraction phase also contained $50.4 \pm 5.7 \mathrm{mM}$ butanol and $123 \pm 40 \mathrm{mM}$ ethanol as well as traces of caproate. Again, neither acetate nor butyrate were present in the extraction phase. 
In conclusion, these findings not only confirm that oleyl alcohol is an efficient hexanol extraction solvent during the fermentation of syngas, but also showed a positive effect on produced hexanol titers by removing the toxic product from the fermentation broth. Intriguingly, this positive effect only occurs at $30{ }^{\circ} \mathrm{C}$ but not at $37^{\circ} \mathrm{C}$. In summary, cultivation at $30^{\circ} \mathrm{C}$ compared to $37^{\circ} \mathrm{C}$ led to a $50 \%$ increase in hexanol titers in the absence of oleyl alcohol and more than a 4 -fold increase in hexanol production in the presence of oleyl alcohol compared to $37^{\circ} \mathrm{C}$.

\section{Analysis Of Cellular Membrane Fatty Acid Composition}

To find a potential explanation for the significant difference on the production and growth behavior at both temperatures investigated, a fatty acid analysis of the cell membrane of $C$. carboxidivorans was performed. We compared the membrane composition at $30^{\circ} \mathrm{C}$ in the presence and absence of hexanol to reveal possible adaptation towards this toxic product. The concentration of $10 \mathrm{mM}$ hexanol was chosen for this experiment. At this concentration we already anticipated adaptation to the alcohol without too severe toxic effects that might lead to differences in growth behavior (i.e. growth phase at cell harvest), which would also lead to potential differences in cell membrane composition.

It has already been shown for $E$. coli that both, growth at increased temperatures as well as growth in the presence of hexanol led to a shift towards more saturated fatty acids [28]. Most interestingly, we could not find adaptation of $C$. carboxidivorans cell wall lipid composition when grown in the presence of $10 \mathrm{mM}$ hexanol (Supplementary Table 1). However, comparing cells grown at $30^{\circ} \mathrm{C}$ to cells grown at $37^{\circ} \mathrm{C}$, we found a shift in fatty acid composition towards more saturated fatty acids and overall less diversity in the membrane composition at the higher growth temperature. While at $30{ }^{\circ} \mathrm{C} 75.7 \pm 6.6 \%$ of the membrane consisted of compounds with a chain length of 16 carbons, this was increased to $91.3 \pm$ $0.4 \%$ at $37^{\circ} \mathrm{C}$. Furthermore, at $30^{\circ} \mathrm{C}$ the membrane composition was more diverse with percentages of both longer and shorter lipids increased compared to $37^{\circ} \mathrm{C}$ (Fig. 5). Within 16 carbon compounds there was a higher percentage of saturated lipids (mostly palmitic acid and $16: 0$ vinyl ether), detected at $37^{\circ} \mathrm{C}$, while mostly $16: 1$ cis 9 and $16: 1$ cis 11 were increased at $30^{\circ} \mathrm{C}$ compared to the higher growth temperature. The amount of saturated lipids shifted from $42.6 \pm 1.9 \%$ at $30^{\circ} \mathrm{C}$ to $65.7 \pm 0.4 \%$ at $37^{\circ} \mathrm{C}$ with the correlated decrease in (mono-) unsaturated lipids. The only polyunsaturated fatty acid detected was $15: 2$ with $2.5 \pm 1.6 \%$ at $30^{\circ} \mathrm{C}$ and $1.1 \pm 0.5 \%$ at $37^{\circ} \mathrm{C}$. Cyclic or branched chain fatty acids were only found in low concentrations of $\leq 0.8 \%$ per molecular species.

\section{Utilization Of Plant Oils As Extraction Solvents}

As discussed earlier, oleyl alcohol has already widely been used as an extraction solvent in fermentations with clostridia. Important factors for this application are mainly biocompatibility, selectivity for the targeted product, stability of the solvent and bulk price. Oleyl alcohol can be produced from oleic acid ester isolated from animal and plant oils [29]. Using plant oils directly as extraction solvents would conceptually lead to energy and financial savings and more sustainable production. Corn oil and 
sunflower seed oil were chosen as exemplary plant based solvents. In comparison, the lab scale costs for the extraction solvents used per liter were $300.89 €$ for oleyl alcohol, $75.20 €$ for sunflower seed oil and $70.40 €$ for corn oil. All extraction solvents were supplied by Sigma Aldrich Chemie (Merck, Darmstadt, Germany). In bulk use for larger scale fermentations the prices, especially of plant oils, would conceivably drop considerably. To investigate the viability of plant oils as alternative extraction solvents, cells were grown in $4.5 \mathrm{~mL}$ Medium supplemented with the respective extraction solvent in $250 \mathrm{~mL}$ anaerobic flasks with 1 bar overpressure syngas. The small culture volume circumvented the need to renew the gas phase since only final hexanol titers and optical densities were investigated. The experiment was done twice with $10 \%$ extraction phase and once with $20 \%$ extraction phase, showing no positive influence of increased solvent volume in final hexanol titers. Biomass measured as $\mathrm{OD}_{600}$ reached in this experiment was $4.9 \pm 0.8$ with oleyl alcohol, $3.7 \pm 0.6$ with sunflower oil and $4.4 \pm 0.8$ with corn oil (Fig. $6 \mathrm{~A}$ ). Final hexanol titers were similar with all three extraction solvents but extraction efficiency was less pronounced in the plant oils (Fig. 6B). With $10 \%$ solvent, when oleyl alcohol was used, $85 \pm 2 \%$ of the produced hexanol were found in the extraction phase, while only $41 \pm 10 \%$ were located in the sunflower oil and 43 $\pm 6 \%$ in the corn oil extraction phase.

\section{Discussion}

\section{Impact of temperature on growth and hexanol toxicity}

Clostridium carboxidivorans $\mathrm{P} 7$ has the unusual ability to produce hexanol directly from syngas, but the toxicity of hexanol has not been determined in this species and current maximum titers may be limited by product toxicity. Accordingly, we tested the acute toxicity of hexanol in C. carboxidivorans $\mathrm{P} 7$ and $C$. ljungdahlii (which does not produce hexanol) and found that almost all cells were killed by exposure to $20 \mathrm{mM}(2 \mathrm{~g} / \mathrm{L})$ hexanol for $24 \mathrm{~h}$ at $37^{\circ} \mathrm{C}$. Intuitively, one might expect greater hexanol tolerance in a natural producer than in an organism without natural exposure to this compound. However, the similar sensitivity we observed for both species probably reflects the natural environment of $C$. carboxidivorans P7, which was first isolated from an agricultural settling lagoon [7]. This environment is not an optimized medium for hexanol production, so the titers of hexanol would be much lower than achieved in the laboratory, and in any case the lagoon would allow hexanol to diffuse away from its source, reducing the local concentration. Hexanol production by $C$. carboxidivorans $\mathrm{P} 7$ in its natural environment is therefore unlikely to impose selection pressure for improved tolerance. This may also explain why the fatty acid composition of $C$. carboxidivorans cell membranes did not adapt in the presence of sub-lethal hexanol titers $\left(10 \mathrm{mM}\right.$ at $\left.30^{\circ} \mathrm{C}\right)$.

The apparent $\mathrm{IC}_{50}$ of hexanol for $C$. carboxidivorans was $17.5 \pm 1.6 \mathrm{mM}(1.8 \mathrm{~g} / \mathrm{L})$ at $30{ }^{\circ} \mathrm{C}$ and $11.8 \pm$ $0.6 \mathrm{mM}(1.2 \mathrm{~g} / \mathrm{L})$ at $37^{\circ} \mathrm{C}$. This represents a $48 \%$ increase in hexanol tolerance at $30^{\circ} \mathrm{C}$ compared to the standard cultivation temperature of $37^{\circ} \mathrm{C}$, although the doubling time only increased by $33 \%$ at the lower temperature. Because growth at the lower temperature also increased biomass yields, fermentation at 
$30^{\circ} \mathrm{C}$ appears to offer a favorable tradeoff between growth and product tolerance during hexanol production.

On the second day of growth in the presence of hexanol at $30^{\circ} \mathrm{C}$, exponential growth ceased suggesting the cells were experiencing stress. Significant growth impairment was observed in the presence of $12 \mathrm{mM}$ hexanol. This suggests that the toxicity of hexanol increases with longer exposure times or that the synthesis of natural products (mostly acetate and ethanol at this stage) increases stress due to cotoxicity. The increase in turbidity following the addition of hexanol (Fig. 1A,B) may impact the observed effect of hexanol on cell growth in the $\mathrm{IC}_{50}$ experiments. For example, the apparent doubling observed at $30{ }^{\circ} \mathrm{C}$ in the presence $20 \mathrm{mM}$ hexanol may well reflect the hexanol-induced increase in turbidity rather than genuine cell growth. The immediate effect of hexanol on turbidity seems to represent an interaction between cell density and hexanol concentration, so it is not possible to calculate adjusted growth rates from the observed data. This might result in artefactual higher apparent growth rates in the presence of increasing hexanol titers. The genuine $\mathrm{IC}_{50}$ value is therefore likely to be slightly lower than the reported value in each experiment.

The $\mathrm{IC}_{50}$ value of hexanol we observed was much lower than the values previously reported for ethanol $(20-25 \mathrm{~g} / \mathrm{L})$ and butanol $(4.12-6.36 \mathrm{~g} / \mathrm{L})[21,22]$. The higher toxicity of longer-chain alcohols is anticipated because such products are less polar and interact more strongly with lipid membranes [23, 30]. Hexanol toxicity mainly reflects its effect on membrane fluidity, as demonstrated in $E$. coli [31]. The macroscopic flocculation of $C$. carboxidivorans $\mathrm{P7}$ cells in the presence of higher concentrations of hexanol indicates a similar mode of toxicity in Clostridium spp. A different mode of toxicity has been demonstrated in the yeast Saccharomyces cerevisiae, where hexanol inhibited protein synthesis. Strains with enhanced $n$-hexanol tolerance were shown to carry mutations in the elF2 and elF2B complexes that prevented the negative effects of $n$-hexanol on the translation initiation complex, allowing significantly improved growth in the presence of $0.15 \% n$-hexanol compared to the wild-type strain [32]. Despite the differences between the protein synthesis apparatus in eukaryotes and prokaryotes, investigations using an analogous approach might also help to improve hexanol tolerance in Clostridium spp.

Both $C$. carboxidivorans P7 and C. Ijungdahlii appear less sensitive to hexanol than E. coli, the latter showing $45 \%$ inhibition of exponential growth in the presence of $0.625 \mathrm{~g} / \mathrm{L}(6.3 \mathrm{mM})$ hexanol [23] whereas $C$. carboxidivorans $\mathrm{P} 7$ began to experience growth inhibition at approximately double this concentration (10-12 mM) in our experiments. The $I_{50}$ value of hexanol for an enrichment culture of methanogens was $1.5 \mathrm{~g} / \mathrm{L}$ [33], which is similar to the values reported here.

\section{Cell Membrane Adaptation To Temperature And Hexanol}

To find a potential explanation for increasing hexanol tolerance and improved hexanol productivity at lower temperatures, we investigated the fatty acid composition of $C$. carboxidivorans. We found that the abundance of saturated $\mathrm{C} 16$ fatty acids in the cell membrane nearly doubled when the temperature was 
increased from $30^{\circ} \mathrm{C}$ to $37^{\circ} \mathrm{C}$, at the expense of mostly mono-unsaturated fatty acids with the same chain length. In E. coli the same temperature increase also triggered a shift towards more saturated fatty acids, and interestingly the same shift was observed when E. coli was exposed to $0.08 \%$ hexanol even when the temperature was not changed [28]. Furthermore, longer and more saturated fatty acids accumulate in the membrane of Clostridium pasteurianum during $n$-butanol fermentation [34] as well as in $C$. acetobutylicum following a shift to higher temperatures, or in the presence of either 0.5 or $1 \mathrm{~g} / \mathrm{l}$ hexanol [35]. The latter study reported a MIC for hexanol in C. acetobutylicum of $1.4 \mathrm{~g} / \mathrm{L}$ [35].

We determined the membrane composition of $C$. carboxidivorans in the presence of $1 \mathrm{~g} / \mathrm{L}(10 \mathrm{mM})$ hexanol at $30^{\circ} \mathrm{C}$. Given the effects of this hexanol concentration and the similar MICs reported for $C$. acetobutylicum and determined for $C$. carboxidivorans in this study, we anticipated that $C$. carboxidivorans membranes would adapt when exposed to this concentration of hexanol. Intriguingly, we observed no such adaptation, which could be explained in several ways: (1) C. carboxidivorans may be intrinsically unable to adapt to higher concentrations of hexanol; (2) adaptation may be possible, but the mechanism may not be lipid-dependent and thus was not detected in our experiments (for example adaptation may involve membrane proteins); and (3) even though the cells were adapted to grow in the presence of hexanol before fatty acid analysis, long-term adaptation to higher titers may lead to different findings in terms of membrane composition.

The inhibitory effects of higher temperatures and hexanol are both likely to reflect, at least in part, an increase in membrane fluidity and leakage [36]. This can be addressed by the assembly of a more homogenous membrane with a higher content of saturated fatty acids or by the conversion of cisunsaturated fatty acids to their trans counterparts, the latter allowing tighter packaging [37]. However, trans-unsaturated fatty acids are not produced naturally in E. coli or S. saccharomyces [38] and we did not detect them in $C$. carboxidivorans. In contrast, Pseudomonsa putida can convert cis to trans unsaturated fatty acids due to the presence of a cis-trans isomerase [39]. When this enzyme was expressed in $E$. coli, the resulting strain was less sensitive to higher temperatures and various inhibitory compounds, including butanol [38]. A similar approach might allow the development of engineered $C$. carboxidivorans strains with greater hexanol tolerance.

\section{Impact Of Temperature On Hexanol Production And Extraction}

Extraction with oleyl alcohol at $30^{\circ} \mathrm{C}$ showed promising detoxification results and increased the final hexanol titers by nearly 2.5 -fold to $2.4 \mathrm{~g} / \mathrm{L}(23.9 \mathrm{mM})$. Our results therefore indicate a strong correlation between the inhibitory hexanol concentration of 10-12 mM and the highest hexanol titers of $13.0 \mathrm{mM}$ produced by $C$. carboxidivorans P7 thus far [19]. Biocompatible extraction solvents such as oleyl alcohol remove lipophilic toxic products from the fermentation broth and thus achieve higher production titers. However, the finding that in situ extraction neither increased cell viability nor hexanol production at $37^{\circ} \mathrm{C}$ was unexpected. This is most likely explained by the initially faster production of acetate and ethanol at 
higher growth temperatures. These compounds display inhibitory effects which cannot be mediated by the extraction solvent since they are not extracted by oleyl alcohol due to their higher polarity and mostly accumulate in the aqueous phase.

With product toxicity addressed, other factors that limit hexanol production can be investigated. The recently reported two-step fermentation process provides a constant influx of new substrate by holding the first fermenter at a higher $\mathrm{pH}$ for acetogenesis and the second at a lower $\mathrm{pH}$ with cell retention for the production of longer-chain compounds, mostly alcohols [20]. The combination of two-step fermentation with in situ extraction in the second fermenter could therefore increase hexanol titers and running times even further, especially if the extraction solvent were replenished to allow for continuous hexanol extraction.

\section{Plant oils for in situ hexanol extraction}

The widely-used extraction solvent oleyl alcohol can be produced by the hydrogenation of oleic acid esters derived from animal or plant oils [29]. The direct use of plant oils could reduce the cost of reagents, therefore we tested corn oil and sunflower oil as potential replacements due to their similar composition and anticipated similar performance. Both plant oils contained approximately similar amounts of oleic acid (18:1), with $29.1 \%$ and $30.6 \%$, respectively. Furthermore, corn oil and sunflower oil respectively contain $11.8 \%$ and $6.5 \%$ palmitic acid (16:0), $1.6 \%$ and $3.6 \%$ stearic acid (18:0) and $55.4 \%$ and $56.8 \%$ linoleic acid (18:2).

We found that biomass yields were barely affected in the presence of corn oil but declined by $~ 25 \%$ in the presence of sunflower oil. Final hexanol titers were similar with all three extraction solvents but oleyl alcohol achieved the best extraction efficiency with $85 \pm 2 \%$ of total hexanol in the $10 \%$ extraction phase compared to $43 \pm 6 \%$ for the corn oil and $41 \pm 10 \%$ for the sunflower oil. This tradeoff between production costs and extraction efficiency will need to be evaluated for each application on a case-by-case basis, and is highly dependent on the reusability of the extraction solvent during industrial processes, which we did not investigate in this study.

\section{Conclusions}

We have shown that product toxicity is an important factor limiting hexanol production during the fermentation of syngas by $C$. carboxidivorans P7. The addition of biocompatible solvents led to a significant increase in hexanol production and facilitates efficient and selective product extraction at $30{ }^{\circ} \mathrm{C}$, whereas in situ extraction had no positive effect on growth or production occur at $37^{\circ} \mathrm{C}$.

Hexanol tolerance based on $\mathrm{IC}_{50}$ values increased by $48 \%$ when the temperature was reduced from $37^{\circ} \mathrm{C}$ $(11.8 \mathrm{mM} \pm 0.6 \mathrm{mM})$ to $30^{\circ} \mathrm{C}(17.5 \pm 1.6 \mathrm{mM})$ whereas the growth rate decreased by only $25 \%$. In line with the previous findings, hexanol production without extraction is increased by $50 \%$ from $7.0 \mathrm{mM}$ to $10.5 \mathrm{mM}$ at the lower incubation temperature. The fatty acid composition of the cell membrane does not adapt to the presence of $10 \mathrm{mM}$ hexanol, but switching from $37^{\circ} \mathrm{C}$ to $30^{\circ} \mathrm{C}$ led to a significant increase in 
the abundance of (mono-) unsaturated lipids at the expense of saturated 16:0 lipids. Growth inhibition due to product toxicity was eliminated by the addition of a biocompatible solvent at a low growth temperature of $30^{\circ} \mathrm{C}$. Having addressed this challenge, $C$. carboxidivorans was able to convert syngas into hexanol with titers of $23.9 \mathrm{mM}(2.4 \mathrm{~g} / \mathrm{L})$, which is $80 \%$ higher than the best previous reported results [19]. We now have an opportunity to increase titers far beyond current maximum levels by additional strain development and the further optimization of process parameters.

\section{Methods}

\section{Chemicals, strains and bacteria cultivation}

All chemicals were supplied by Sigma-Aldrich Chemie (Merck, Darmstadt, Germany) or Carl Roth (Karlsruhe, Germany). All gases were supplied by Westfalen (Münster, Germany). Type strains of $C$. carboxidivorans P7 (DSM 15243) and C. ljungdahlii (DSM 13528) were obtained from the Deutsche Sammlung von Mikroorganismen und Zellkulturen (DSMZ, Braunschweig, Germany). Both strains were grown in modified Protein Expression Technology Center (PETC) 1754 medium (ATCC, Manassas, VA, USA) buffered at pH 6 with $100 \mathrm{mM}$ BisTris. The modified minimal medium contained $1 \mathrm{~g} / \mathrm{L}$ ammonium chloride, $0.1 \mathrm{~g} / \mathrm{L}$ potassium chloride, $0.2 \mathrm{~g} / \mathrm{L}$ magnesium sulfate heptahydrate, $0.8 \mathrm{~g} / \mathrm{L}$ sodium chloride, $0.1 \mathrm{~g} / \mathrm{L}$ potassium dihydrogen phosphate, $20 \mathrm{mg} / \mathrm{L}$ calcium chloride dehydrate and $1 \mathrm{~g} / \mathrm{L}$ yeast extract. Trace elements and vitamins were prepared as described by ATCC, and $2 \mathrm{mg} / \mathrm{L}$ resazurin was used as a redox indicator to ensure strictly anaerobic conditions in the medium. Batches of medium were autoclaved prior to the addition of vitamins and trace elements from sterile stock solutions and were left overnight in a Whitley A55 Anaerobic Workstation (Don Whitley Scientific, Herzlake, Germany) in an oxygen-free atmosphere comprising $5 \% \mathrm{H}_{2}, 10 \% \mathrm{CO}_{2}$ and $85 \% \mathrm{~N}_{2}$. Lcysteine (final concentration:

$0.75 \mathrm{~g} / \mathrm{L}$ ) was added as a reducing agent. An optimized trace element composition for alcohol production was used for determination of $\mathrm{IC}_{50}$ and hexanol production and extraction experiments, and membrane fatty acid analysis [19].

\section{Determination of hexanol toxicity}

Pre-cultures of $C$. carboxidivorans $\mathrm{P} 7$ and $C$. ljungdahlii were adapted for several generations to grow on modified minimal medium [19] with syngas $\left(33.3 \% \mathrm{CO}_{2}, 33.3 \% \mathrm{CO}\right.$ and $\left.33.3 \% \mathrm{H}_{2}\right)$ as the growth substrate. Adapted cells were used to inoculate 5-mL medium in $25-\mathrm{mL}$ anaerobic glass tubes (Glasgerätebau Ochs, Bovenden/Lenglern, Germany) with rubber stoppers, and the headspace was filled with syngas of the same composition. The cultures were maintained horizontally at $37^{\circ} \mathrm{C}$ with constant agitation at $150 \mathrm{rpm}$. Cell growth was measured using an HI93703 microprocessor turbidity meter (Hanna Instruments Deutschland, Vöhringen, Germany) and the $\mathrm{OD}_{600}$ was calculated using a calibration curve. Once growth was observed (turbidity corresponding to $\mathrm{OD}_{600} 0.2$ ), hexanol was added from a pure, sterile,

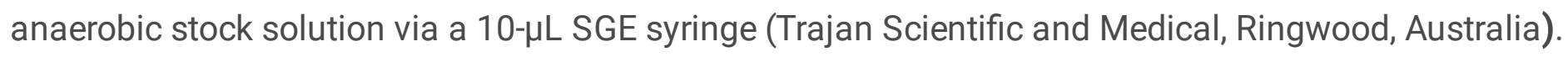
Hexanol extraction with technical grade $85 \%$ oleyl alcohol (Merck) was tested under the same 
experimental conditions as described above. The medium was supplemented with $100 \mathrm{mM}$ hexanol and $5 \%$ (v/v) oleyl alcohol from sterile, anaerobic stock solutions.

\section{Determination of minimal inhibitory concentrations (MIC) and $\mathrm{IC}_{50}$ values}

The onset of growth inhibition was investigated using the same cultivation setup as described above but with optimized trace element composition [19] and an adjusted syngas composition (65\% CO, 15\% $\mathrm{N}_{2}$, $15 \% \mathrm{CO}_{2}$ and $5 \% \mathrm{H}_{2}$ ). The cells were incubated horizontally at the respective temperature while shaking at $150 \mathrm{rpm}$. Cell growth was monitored by turbidimetry and $\mathrm{OD}_{600}$ values were calculated using a calibration curve as above. Malthusian growth during the exponential growth phase was calculated using GraphPad Prism v8 (GraphPad Software, San Diego, CA, USA). Growth rates were normalized against the control without hexanol in the same experiment and were plotted as percentages against the hexanol concentrations added to each culture. Four-factor sigmoidal dose-response curves and $I_{50}$ values were calculated using the same program. Fermentations (independent experiments) were carried out five times at $30^{\circ} \mathrm{C}$ or four times at $37^{\circ} \mathrm{C}$ each comprising three cultures per condition.

\section{Fed-batch bottle fermentation}

Adapted cell cultures were inoculated $\left(O D_{600} 0.01-0.02\right)$ into $25 \mathrm{~mL}$ of modified minimal medium with optimized trace elements [19] in 250-mL serum bottles (Glasgerätebau Ochs, Bovenden/Lenglern, Germany). For the extraction experiments, we added $4 \%$ (v/v) oleyl alcohol as above. Cultures were fed with syngas $\left(65 \% \mathrm{CO}, 15 \% \mathrm{~N}_{2}, 15 \% \mathrm{CO}_{2}\right.$ and $\left.5 \% \mathrm{H}_{2}\right)$ at 1 bar overpressure. The cells were incubated at the respective temperature while shaking at $150 \mathrm{rpm}$. The growth of cells exposed to the extraction solvent was determined by measuring the $\mathrm{OD}_{600}$ after washing the cells by centrifugation $(13,000 \times \mathrm{g}, 1 \mathrm{~min}$, room temperature) and resuspending them in water. The gas phase was renewed after 1, 2, 3 and 4 days. Samples were drawn using a sterile syringe and stored at $20^{\circ} \mathrm{C}$ for subsequent analysis. At the end of the experiment (8 days), the oleyl alcohol and fermentation broth were separated by centrifugation and stored in separate tubes at $-20^{\circ} \mathrm{C}$ for analysis by gas chromatography.

\section{Determination of product concentrations via GC/MS analysis}

The concentrations of fermentation products in the aqueous phase was measured by gas chromatography as previously described [40]. Extraction phase samples were diluted 1:100 in pure methanol and then handled in the same manner as the aqueous samples, although the final hold time during gas chromatography was increased to $12 \mathrm{~min}$.

\section{Determination of membrane fatty acid composition}

Cells were inoculated from adapted exponential-phase pre-cultures and grown overnight in $200 \mathrm{~mL}$ modified minimal medium with optimized trace elements in $2 \mathrm{~L}$ glass bottles with rubber stoppers, fed with syngas $\left(65 \% \mathrm{CO}, 15 \% \mathrm{~N}_{2}, 15 \% \mathrm{CO}_{2}\right.$ and $\left.5 \% \mathrm{H}_{2}\right)$ at 0.6 bar overpressure. When the $\mathrm{OD}_{600}$ reached 
$0.4-0.5$, the bottles were opened, and the cells were aerobically cooled on ice and harvested by centrifugation ( $4000 \mathrm{xg}, 15 \mathrm{~min}, 4^{\circ} \mathrm{C}$ ) before freeze drying overnight in a VaCO5 device (Zirbus Technology GmbH, Bad Grund/Harz, Germany). The membrane fatty acid composition was determined by Deutsche Sammlung von Mikroorganismen und Zellkulturen (DSMZ, Braunschweig, Germany) via $\mathrm{GC} / \mathrm{MS}$ analysis after the following protocol:

Following saponification, methylation and extraction [41, 42], the fatty acid methyl esters (FAMEs) were analyzed by gas chromatography and detected by flame ionization, with peak identification following the Sherlock Microbial Identification System (MIS) (MIDI, Microbial ID, Newark, DE 19711 USA). Peak identification was confirmed by gas chromatography mass spectrometry (GC-MS) using an Agilent Technologies (Santa Clara, CA, USA) GC-MS 7000D device equipped with an Agilent HP-5 ms UI $30 \mathrm{~m} \mathrm{x}$ $250 \mu \mathrm{m} \times 0,25 \mu \mathrm{m}$ column, percentages were calculated by the MIS Standard Software (Microbial ID). An injection volume of $1 \mu \mathrm{l}$ was used with a split ratio of $7.5: 1$ and a helium gas flow of $1.2 \mathrm{ml} / \mathrm{min}$ was applied. The oven temperature was set to an initial temperature of $170^{\circ} \mathrm{C}$, increasing at $3{ }^{\circ} \mathrm{C} / \mathrm{min}$ to $200{ }^{\circ} \mathrm{C}$, then at $5^{\circ} \mathrm{C} / \mathrm{min}$ to $270^{\circ} \mathrm{C}$, then at $120^{\circ} \mathrm{C} / \mathrm{min}$ to $300^{\circ} \mathrm{C}$, followed by a hold for $2 \mathrm{~min}$. The inlet temperature was initially adjusted to $170^{\circ} \mathrm{C}$ and then increased linearly at $200{ }^{\circ} \mathrm{C} / \mathrm{min}$ to $350^{\circ} \mathrm{C}$ followed by a hold for $5 \mathrm{~min}$. The MS parameters were set as follows: auxiliary temperature was $230^{\circ} \mathrm{C}$, source temperature $230^{\circ} \mathrm{C}$, electron impact ionization $70 \mathrm{eV}$ with mass range of $\mathrm{m} / \mathrm{z} 40-600$ or $40-800$, respectively. Peaks were identified based on retention time and mass spectra. To confirm the position of double bonds, samples were derivatized to corresponding dimethyl disulfide adducts [43]. To identify branched-chain fatty acid positions, cyclo-positions and multiple double bonds, samples were derivatized to their 3-pyridylcarbinol ("picolinyl") and/or 4,4-dimethyloxazoline (DMOX) adducts [44-46].

\section{Comparison of different extraction solvents}

Cells were cultivated as described above for the fed-batch experiments. We supplemented a reduced media volume of $4.5 \mathrm{~mL}$ with either $10 \%$ or $20 \%$ oleyl alcohol or plant oils in $250 \mathrm{~mL}$ bottles (as indicated in the results section), to avoid the need for gas renewal during experiments without growth curves. Bottles were inoculated from exponential precultures to $\mathrm{OD}_{600}$ 0.1-0.2. Sunflower seed oil from Helianthus annuus (88921-250ML-F) and corn oil (C8267-500ML) were both purchased from SigmaAldrich Chemie (Merck, Darmstadt, Germany), filter-sterilized and stored under anoxic conditions for several days before use.

\section{Declarations}

\section{Availability of data and materials}

\section{All data generated or analyzed during this study are included in this published article and supplements or are available from the corresponding author on reasonable request.}




\section{Competing interests}

The authors declare that they have no competing interests.

\section{Funding}

This work was funded by the German Ministry for Education and research (BMBF) as part of the BioCOnversion project (grant number 03INT513B).

\section{Authors' contributions}

SJ, GP and PK designed the experiments. The experiments were conducted by PK and the data were analyzed by all authors. GP and SJ conceived the project. The manuscript was written by PK and all authors read and approved the final manuscript.

\section{Acknowledgements}

We would like to thank Chiara Weickardt for technical assistance and Richard Twyman for critical reading of the manuscript.

\section{Consent for publication}

Not applicable.

\section{Ethical approval and consent to participate}

Not applicable.

\section{References}

1. Köpke M, Noack S, Dürre P: The past, present, and future of biofuels-biobutanol as promising alternative. In: Biofuel Production-Recent Developments and Prospects. IntechOpen; 2011.

2. Dürre P. Biobutanol: an attractive biofuel. Biotechnol J. 2007;2(12):1525-34.

3. Haas T, Krause R, Weber R, Demler M, Schmid G. Technical photosynthesis involving $\mathrm{CO}_{2}$ electrolysis and fermentation. Nature Catalysis. 2018;1(1):32-9.

4. Drake HL, Gossner AS, Daniel SL. Old acetogens, new light. Ann N Y Acad Sci. 2008;1125:100-28.

5. Daniell J, Köpke M, Simpson SD. Commercial Biomass Syngas Fermentation. Energies. 2012;5(12):5372-417. 
6. Griffin DW, Schultz MA: Fuel and Chemical Products from Biomass Syngas: A Comparison of Gas Fermentation to Thermochemical Conversion Routes. Wiley Online Library 2012.

7. Liou JS, Balkwill DL, Drake GR, Tanner RS. Clostridium carboxidivorans sp. nov., a solvent-producing clostridium isolated from an agricultural settling lagoon, and reclassification of the acetogen Clostridium scatologenes strain SL1 as Clostridium drakei sp. nov. Int J Syst Evol Microbiol. 2005;55(Pt 5):2085-91.

8. Fernandez-Naveira A, Veiga MC, Kennes C. Selective anaerobic fermentation of syngas into either C2C6 organic acids or ethanol and higher alcohols. Bioresour Technol. 2019;280:387-95.

9. Fernandez-Naveira A, Abubackar HN, Veiga MC, Kennes C. Production of chemicals from C1 gases $\left(\mathrm{CO}, \mathrm{CO}_{2}\right)$ by Clostridium carboxidivorans. World J Microbiol Biotechnol. 2017;33(3):43.

10. Phillips JR, Atiyeh HK, Tanner RS, Torres JR, Saxena J, Wilkins MR, Huhnke RL. Butanol and hexanol production in Clostridium carboxidivorans syngas fermentation: Medium development and culture techniques. Bioresour Technol. 2015;190:114-21.

11. Schuchmann K, Müller V. Autotrophy at the thermodynamic limit of life: a model for energy conservation in acetogenic bacteria. Nat Rev Microbiol. 2014;12(12):809-21.

12. Müller V. Energy conservation in acetogenic bacteria. Appl Environ Microbiol. 2003;69(11):6345-53.

13. Bertsch J, Müller V. Bioenergetic constraints for conversion of syngas to biofuels in acetogenic bacteria. Biotechnology for biofuels. 2015;8(1):210.

14. Husemann MH, Papoutsakis ET. Solventogenesis in Clostridium acetobutylicum fermentations related to carboxylic acid and proton concentrations. Biotechnol Bioeng. 1988;32(7):843-52.

15. Dürre P, Hollergschwandner C. Initiation of endospore formation in Clostridium acetobutylicum. Anaerobe. 2004;10(2):69-74.

16. Jones DT, Woods DR. Acetone-butanol fermentation revisited. Microbiol Rev. 1986;50(4):484-524.

17. Long S, Jones DT, Woods DR. Sporulation of Clostridium acetobutylicum P262 in a Defined Medium. Appl Environ Microbiol. 1983;45(4):1389-93.

18. Alsaker KV, Paredes C, Papoutsakis ET. Metabolite stress and tolerance in the production of biofuels and chemicals: gene-expression-based systems analysis of butanol, butyrate, and acetate stresses in the anaerobe Clostridium acetobutylicum. Biotechnol Bioeng. 2010;105(6):1131-47.

19. Shen S, Gu Y, Chai C, Jiang W, Zhuang Y, Wang Y. Enhanced alcohol titre and ratio in carbon monoxide-rich off-gas fermentation of Clostridium carboxidivorans through combination of trace metals optimization with variable-temperature cultivation. Bioresour Technol. 2017;239:236-43.

20. Doll K, Ruckel A, Kampf P, Wende M, Weuster-Botz D. Two stirred-tank bioreactors in series enable continuous production of alcohols from carbon monoxide with Clostridium carboxidivorans.

Bioprocess Biosyst Eng. 2018;41(10):1403-16.

21. Fernandez-Naveira A, Abubackar HN, Veiga MC, Kennes C. Carbon monoxide bioconversion to butanolethanol by Clostridium carboxidivorans: kinetics and toxicity of alcohols. Appl Microbiol Biotechnol. 2016;100(9):4231-40. 
22. Ramio-Pujol S, Ganigue R, Baneras L, Colprim J. Effect of ethanol and butanol on autotrophic growth of model homoacetogens. FEMS Microbiol Lett 2018, 365(10).

23. Wilbanks B, Trinh CT. Comprehensive characterization of toxicity of fermentative metabolites on microbial growth. Biotechnol Biofuels. 2017;10:262.

24. Lauer I, Philipps G, Jennewein S. Syngas fermentation: Toxicity analysis of potential products on Clostridium ljungdahlii. In: ClostridiumXV: 18-19.09.2018; TU Munich, Freising, Germany. 2018.

25. Roffler SR, Blanch HW, Wilke CR. In situ extractive fermentation of acetone and butanol. Biotechnol Bioeng. 1988;31(2):135-43.

26. Jeon BS, Moon C, Kim BC, Kim H, Um Y, Sang BI. In situ extractive fermentation for the production of hexanoic acid from galactitol by Clostridium sp. BS-1. Enzyme Microb Technol. 2013;53(3):143-51.

27. Ramio-Pujol S, Ganigue R, Baneras L, Colprim J: Incubation at 25 degrees $C$ prevents acid crash and enhances alcohol production in Clostridium carboxidivorans P7. Bioresour Technol 2015, 192:296303.

28. Berger B, Carty CE, Ingram LO. Alcohol-induced changes in the phospholipid molecular species of Escherichia coli. J Bacteriol. 1980;142(3):1040-4.

29. Bouveault L, Blanc G. Hydrogenation of the Ether of the Acids Furthermore Possessing the Etheroxide or Acetal Functions. Bull Soc Chim Fr. 1904;31:1210-3.

30. Weber FJ: Toluene: biological wastegas treatment, toxicity and microbial adaptation: Weber; 1995.

31. Ingram LO, Vreeland NS. Differential effects of ethanol and hexanol on the Escherichia coli cell envelope. J Bacteriol. 1980;144(2):481-8.

32. Davis Lopez SA, Griffith DA, Choi B, Cate JHD, Tullman-Ercek D. Evolutionary engineering improves tolerance for medium-chain alcohols in Saccharomyces cerevisiae. Biotechnol Biofuels. 2018;11:90.

33. Blum DJ, Speece R. A database of chemical toxicity to environmental bacteria and its use in interspecies comparisons and correlations. Research Journal of the Water Pollution Control Federation 1991:198-207.

34. Venkataramanan KP, Kurniawan Y, Boatman JJ, Haynes CH, Taconi KA, Martin L, Bothun GD, Scholz C. Homeoviscous response of Clostridium pasteurianum to butanol toxicity during glycerol fermentation. J Biotechnol. 2014;179:8-14.

35. Lepage $C$, Fayolle F, Hermann M, Vandecasteele J. Changes in membrane lipid composition of Clostridium acetobutylicum during acetone-butanol fermentation: effects of solvents, growth temperature and pH. Microbiology. 1987;133(1):103-10.

36. Ingram LON, Buttke TM: Effects of alcohols on micro-organisms. In: Advances in microbial physiology. vol. 25: Elsevier; 1985: 253-300.

37. Holtwick R, Meinhardt F, Keweloh H. cis-trans isomerization of unsaturated fatty acids: cloning and sequencing of the cti gene from Pseudomonas putida P8. Appl Environ Microbiol. 1997;63(11):4292-7. 
38. Tan Z, Yoon JM, Nielsen DR, Shanks JV, Jarboe LR. Membrane engineering via trans unsaturated fatty acids production improves Escherichia coli robustness and production of biorenewables. Metab Eng. 2016;35:105-13.

39. Diefenbach $\mathrm{R}$, Heipieper $\mathrm{H}-\mathrm{J}$, Keweloh $\mathrm{H}$. The conversion of cis into trans unsaturated fatty acids in Pseudomonas putida P8: evidence for a role in the regulation of membrane fluidity. Appl Microbiol Biotechnol. 1992;38(3):382-7.

40. Philipps G, de Vries S, Jennewein S. Development of a metabolic pathway transfer and genomic integration system for the syngas-fermenting bacterium Clostridium ljungdahlii. Biotechnol Biofuels. 2019;12:112.

41. Miller LT. Single derivatization method for routine analysis of bacterial whole-cell fatty acid methyl esters, including hydroxy acids. J Clin Microbiol. 1982;16(3):584-6.

42. Kuykendall L, Roy M, O'neill J, Devine T. Fatty acids, antibiotic resistance, and deoxyribonucleic acid homology groups of Bradyrhizobium japonicum. Int J Syst Evol Microbiol. 1988;38(4):358-61.

43. Moss CW, Lambert-Fair MA. Location of double bonds in monounsaturated fatty acids of Campylobacter cryaerophila with dimethyl disulfide derivatives and combined gas chromatographymass spectrometry. J Clin Microbiol. 1989;27(7):1467-70.

44. Yu Q, Liu B, Zhang J, Huang Z. Location of methyl branches in fatty acids: Fatty acids in uropygial secretion of Shanghai ducks by gas chromatography-mass spectrometry of 4, 4-dimethyloxazoline derivatives. Lipids. 1988;23:804-10.

45. Spitzer V. Structure analysis of fatty acids by gas chromatography-low resolution electron impact mass spectrometry of their 4, 4-dimethyloxazoline derivatives-a review. Progress in lipid research. 1996;35(4):387-408.

46. Harvey D. Picolinyl esters as derivatives for the structural determination of long chain branched and unsaturated fatty acids. Biomedical Mass Spectrometry. 1982;9(1):33-8.

\section{Figures}



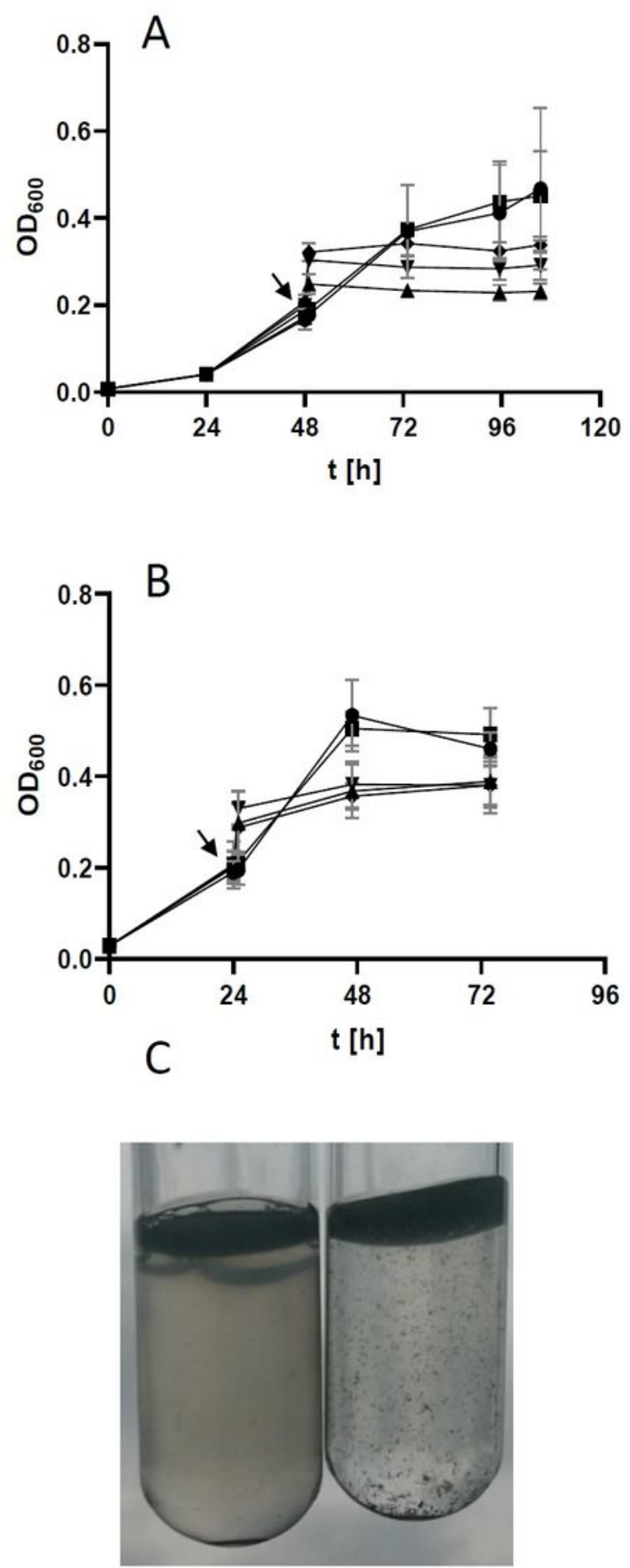

\section{Figure 1}

Acute hexanol toxicity in C. ljungdahlii (A) and C. carboxidivorans P7 (B) at $37^{\circ} \mathrm{C}$. Cells were grown in anaerobic roll tubes with rubber stoppers on syngas ( $\mathrm{CO}, \mathrm{CO} 2$ and $\mathrm{H} 2$ in equal parts) in modified minimal medium. After definitive growth was observed at OD600 $=0.2$, hexanol was added (indicated by the arrow) at concentrations of $0 \mathrm{mM}(\cdot), 10 \mathrm{mM}(\boldsymbol{\square}), 20 \mathrm{mM}(\boldsymbol{\Delta}), 30 \mathrm{mM}(\boldsymbol{\nabla})$ and $40 \mathrm{mM}(\diamond)$, and the gas phase was renewed. Each curve shows a representative experiment from three independent experiments 
each with three cultures per hexanol concentration. (C) Macroscopic effects of $40 \mathrm{mM}$ hexanol on C. carboxidivorans P7 after 3 days (right) compared to the control without hexanol (left).
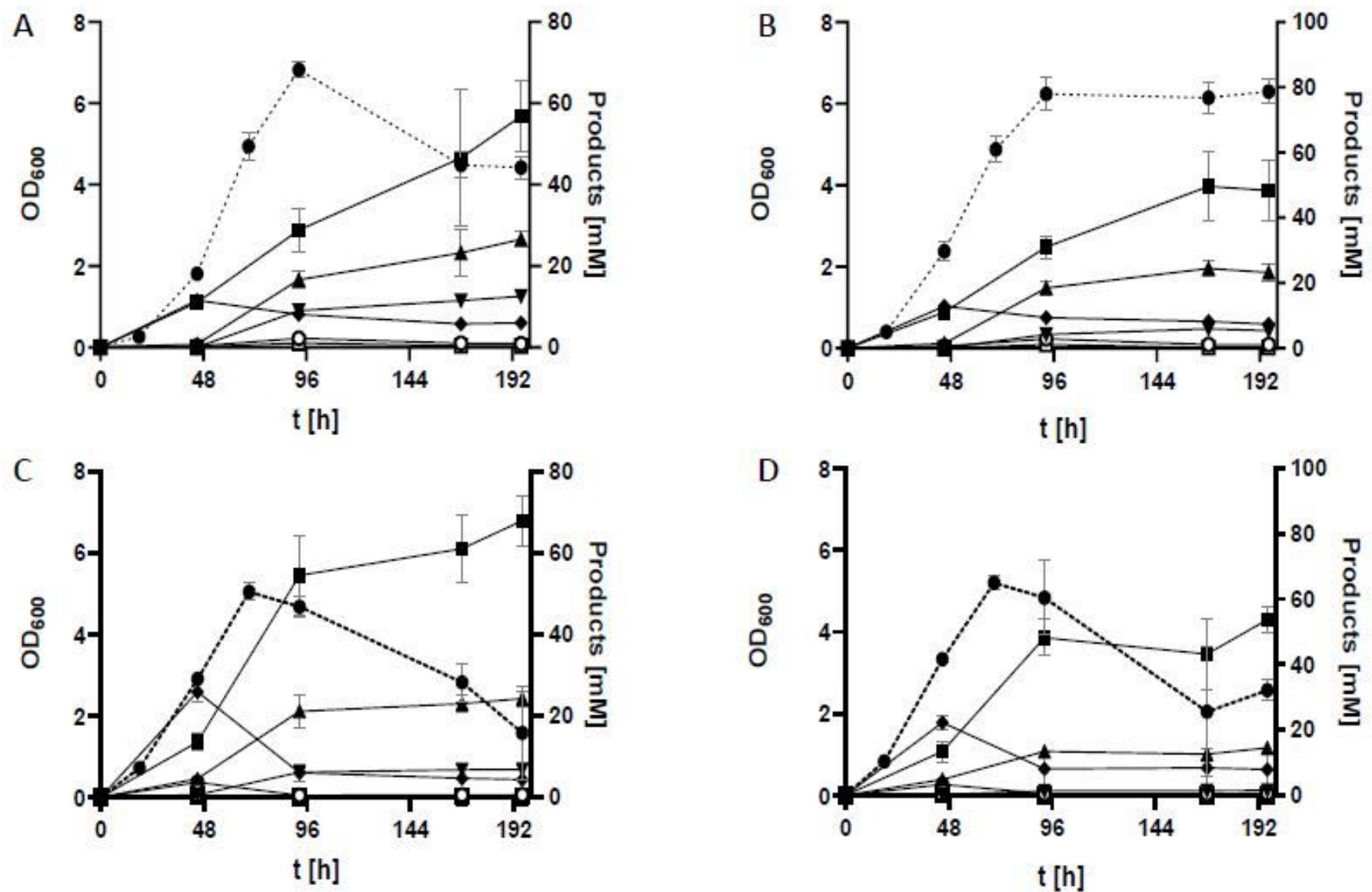

Figure 2

C. carboxidivorans P7 growth curves and products in the aqueous phase with in situ extraction. (A) Cells grown at $30{ }^{\circ} \mathrm{C}$ in modified minimal medium without extraction (B), Cells grown at $30^{\circ} \mathrm{C}$ in the presence of $4 \%(\mathrm{v} / \mathrm{v})$ oleyl alcohol as an extraction solvent (C), Cells grown at $37^{\circ} \mathrm{C}$ in modified minimal medium without extraction (D) Cells grown at $37^{\circ} \mathrm{C}$ in the presence of $4 \%(\mathrm{v} / \mathrm{v})$ oleyl alcohol as extraction solvent. The syngas composition was $65 \% \mathrm{CO}, 15 \% \mathrm{~N} 2,15 \% \mathrm{CO} 2$ and $5 \% \mathrm{H} 2$. Symbols: • OD600, $\square$ ethanol, butanol, $\boldsymbol{\nabla}$ hexanol, $\checkmark$ acetate, $\bigcirc$ butyrate, $\square$ caproate. Each curve shows a representative experiment from at least three independent experiments, each with three cultures per condition tested. 

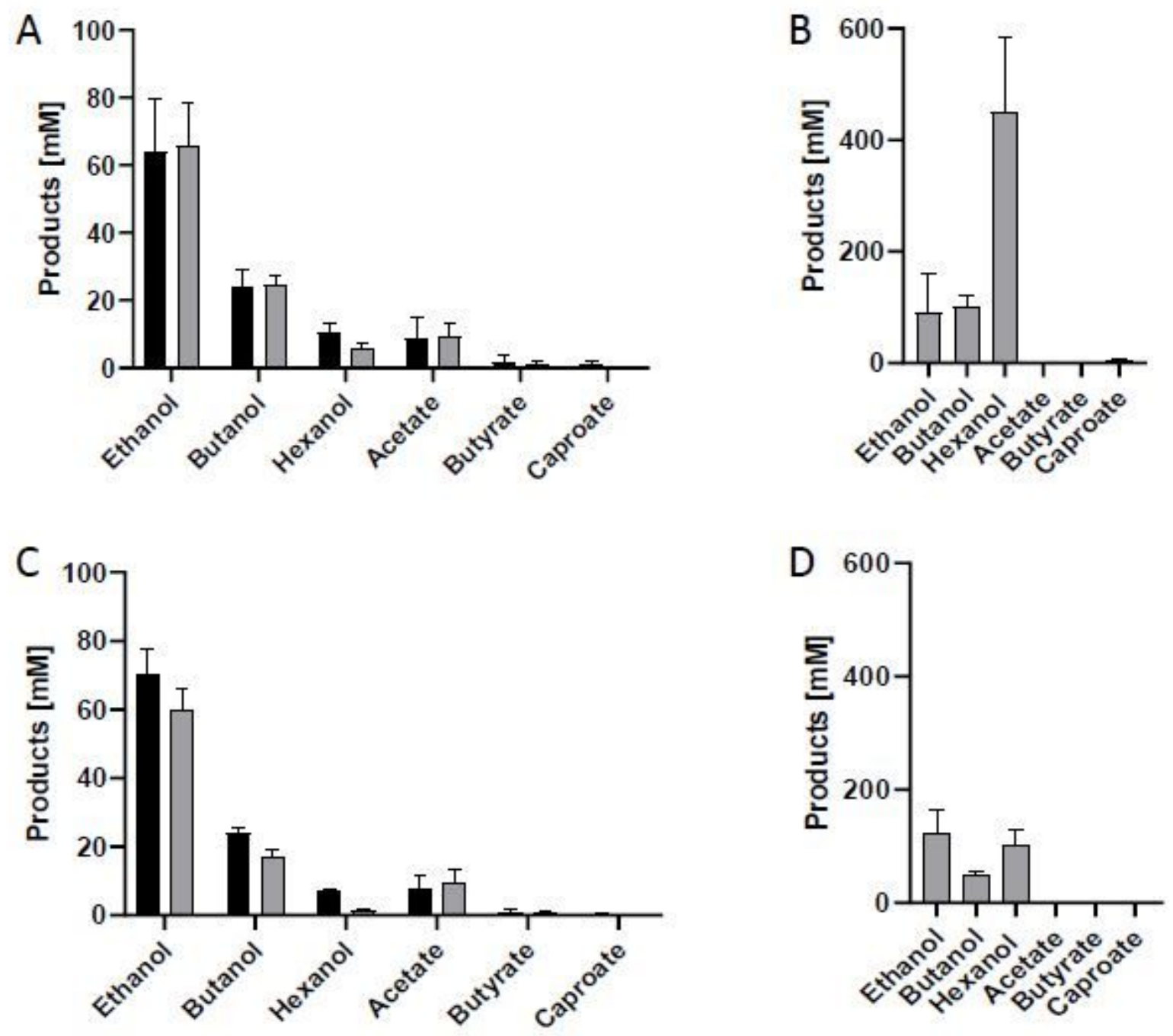

\section{Figure 3}

Final products of C. carboxidivorans P7 in the presence of $4 \%$ oleyl alcohol as an extraction solvent. Cells were grown for 8 days in modified minimal medium with syngas as a growth substrate $(65 \%$ CO, $15 \%$ N2, $15 \% \mathrm{CO} 2$ and $5 \% \mathrm{H} 2$ ). (A) Product titers in the aqueous phase of cultures grown at $30{ }^{\circ} \mathrm{C}$. Black bars indicate the control culture (no oleyl alcohol) and gray bars indicated cultures in the presence of $4 \%(\mathrm{v} / \mathrm{v})$ oleyl alcohol. (B) Product titers in the extraction phase of cultures grown at $30^{\circ} \mathrm{C}$. (C) Product titers in the aqueous phase of cultures grown at $37^{\circ} \mathrm{C}$. Black and gray bars as indicated in panel (A). (D) Product titers in the extraction phase of cultures grown at $37^{\circ} \mathrm{C}$. Data are means \pm standard deviations of at least three independent experiments, each comprising three cultures per condition tested. 

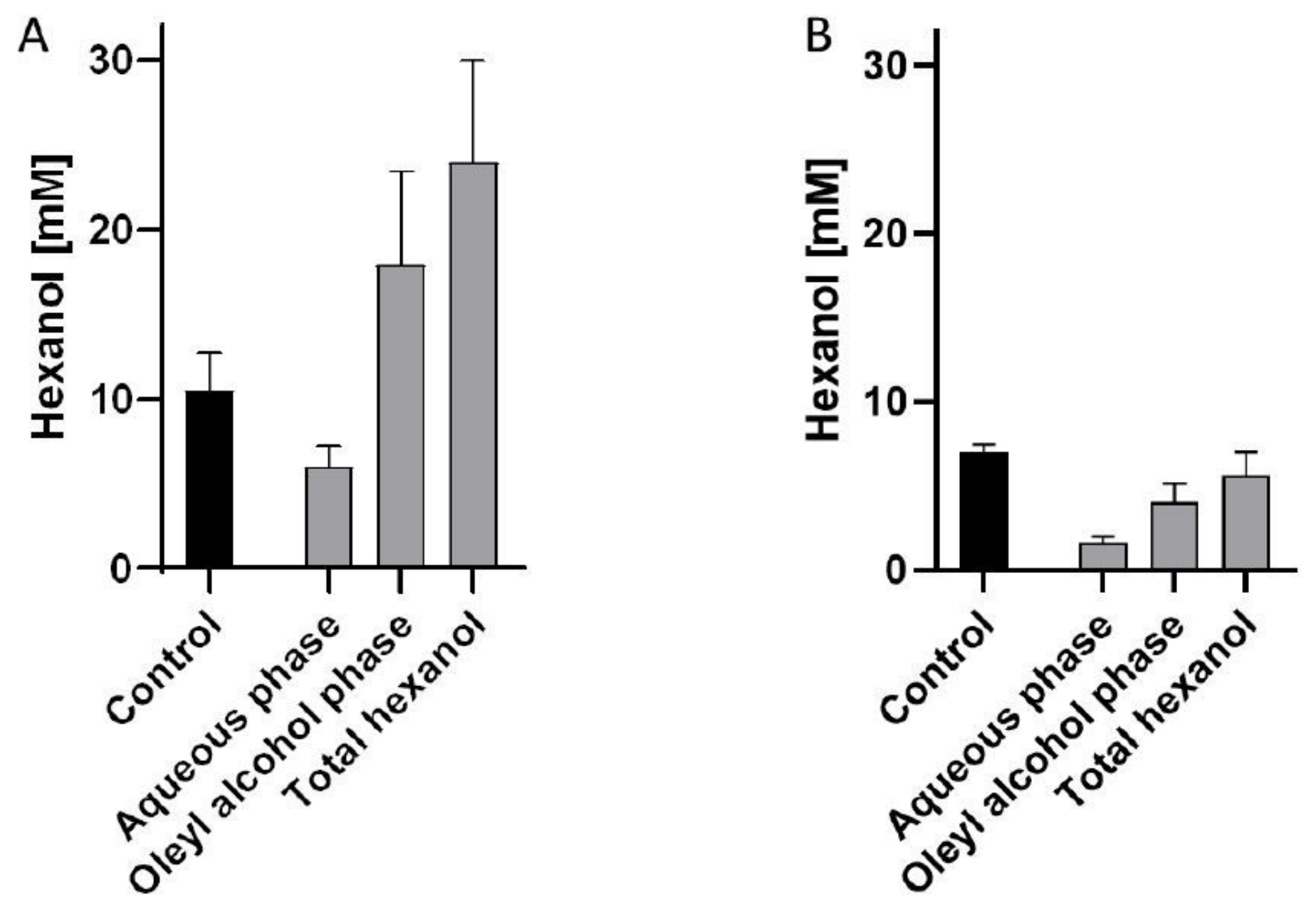

Figure 4

Final hexanol titers of $\mathrm{C}$. carboxidivorans $\mathrm{P} 7$ in the presence of $4 \%$ oleyl alcohol as an extraction solvent. (A) Cultures grown at $30^{\circ} \mathrm{C}$. (B) Cultures grown at $37^{\circ} \mathrm{C}$. Cells were grown in modified minimal medium with syngas as a growth substrate $(65 \% \mathrm{CO}, 15 \% \mathrm{~N} 2,15 \% \mathrm{CO} 2$ and $5 \% \mathrm{H} 2)$. Hexanol titers measured in oleyl alcohol were normalized to the total culture volume to allow for comparison with titers measured in the aqueous phase. Hexanol titers of cultures grown without oleyl alcohol are shown as the negative control (black bars). All data are means \pm standard deviations of at least three independent experiments, each comprising three cultures per condition tested. 




Figure 5

Membrane adaptation of $\mathrm{C}$. carboxidivorans grown with syngas at $30^{\circ} \mathrm{C}$ (white bars) and $37^{\circ} \mathrm{C}$ (black bars). Bars represent sums of percentages of lipid compounds of the same chain length and saturation to show overall trends in composition. Branched chain fatty acids are not shown separately, because they represent $\leq 0.8 \%$ of the total per molecular species. Percentages are shown as means \pm standard deviations of two independent experiments with one technical replicate per condition tested. Insert box shows detailed analysis of 16 carbon lipids. Abbreviations: FAME, fatty acid methyl ester, ALDE, aldehyde, DME, dimethylacetal, ISO, iso-branched-chain fatty acid; CIS 9/CIS 11: position of double bond in unsaturated fatty acids. Full details are provided in the supplementary table 1. 

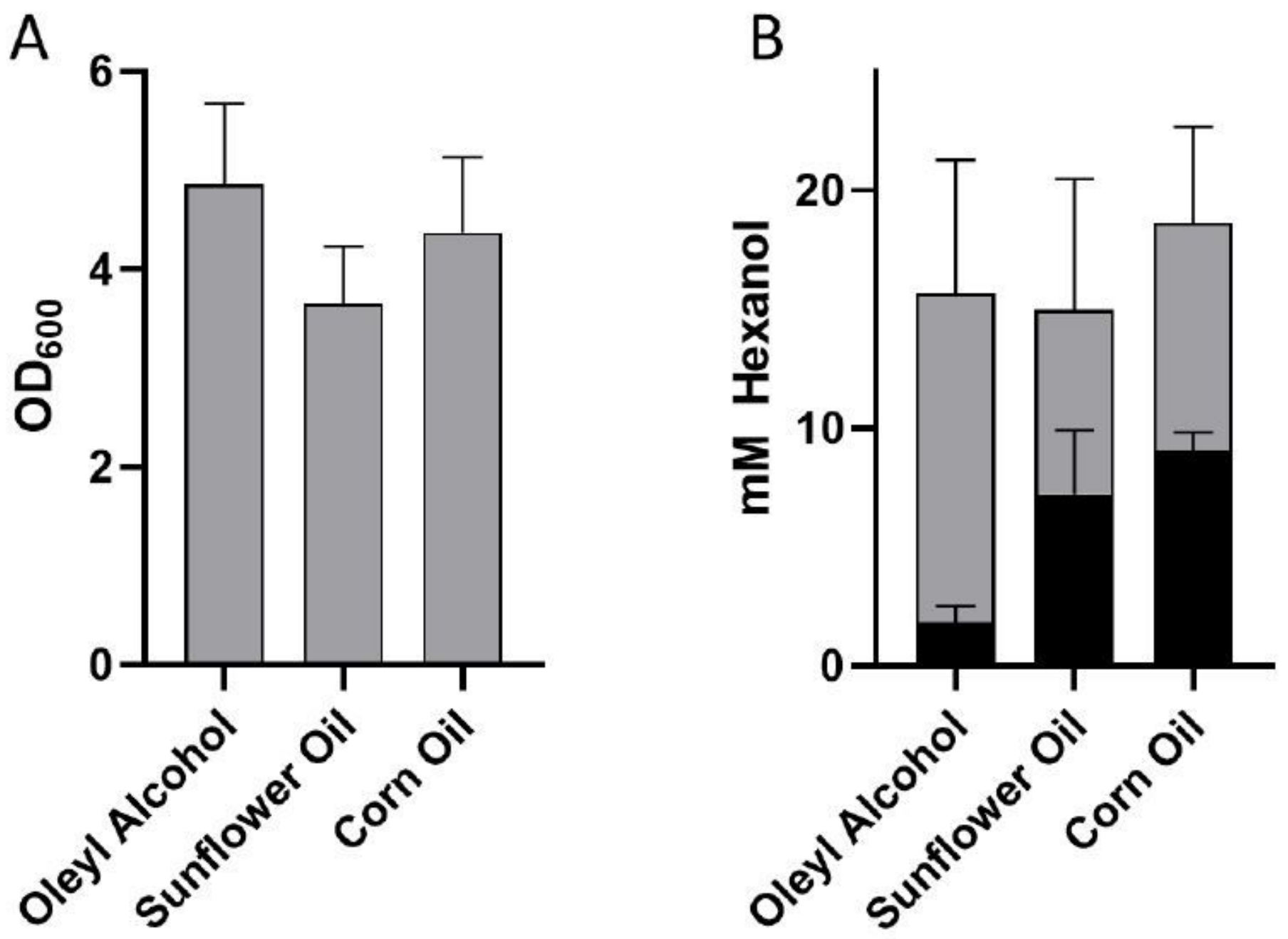

Figure 6

Biomass yields (OD600) and hexanol production in the presence of different extraction solvents. Cells were grown for 7 days in modified minimal medium with 1 bar overpressure of syngas as a growth substrate $(65 \% \mathrm{CO}, 15 \% \mathrm{~N} 2,15 \% \mathrm{CO} 2$ and $5 \% \mathrm{H} 2)$. Hexanol titers measured in the extraction phase were normalized to the whole culture volume and are shown as gray bars. Hexanol titers measured in the aqueous phase are shown as black bars. All data are means \pm standard deviations of eight cultures from three independent experiments.

\section{Supplementary Files}

This is a list of supplementary files associated with this preprint. Click to download.

- SupplementaryTable1.pdf

- SupplementaryFigure1.pdf 